$05,06,12$

\title{
Глицин-нитратный синтез твердых растворов метатитаната бария-стронция
}

\author{
( Д.Н. Белышева ${ }^{1}$, О.Ю. Синельщикова ${ }^{1}$ ฯ , Н.Г. Тюрнина ${ }^{1}$, З.Г. Тюрнина ${ }^{1}$, С.И. Свиридов ${ }^{1}$, \\ А.В. Тумаркин ${ }^{2}$, М.В. Злыгостов ${ }^{2}$, В.Л. Уголков ${ }^{1}$ \\ ${ }^{1}$ Институт химии силикатов им. И.В. Гребенщикова РАН, \\ Санкт-Петербург, Россия \\ ${ }^{2}$ Санкт-Петербургский государственный электротехнический университет „ЛЭТИ“, \\ Санкт-Петербург, Россия \\ ฯ E-mail: sinelshikova@mail.ru, turnina.ng@iscras.ru
}

Поступила в Редакцию 16 июля 2019 г.

В окончательной редакции 16 июля 2019 г.

Принята к публикации 25 июля 2019 г.

Исследовано влияние состава глицин-нитратных композиций на полноту образования твердых растворов метатитаната бария-стронция. Показано, что разложение всех рассмотренных глицин-нитратных композиций начинается при температуре $180^{\circ} \mathrm{C}$, но в зависимости от содержания глицина и $p H$-композиции имеет различный характер. Оптимальным условием для формирования однофазных продуктов является режим объемного горения, достигаемый при превышении содержания восстановителя над окислителем в составе композиции. Такие составы позволяют получать наноразмерные порошки твердых растворов $\mathrm{Ba}_{1-x} \mathrm{Sr}_{x} \mathrm{TiO}_{3}$ $(0 \leq x \leq 0.4)$ прокаливанием при температуре $550^{\circ} \mathrm{C}$, а также вводить их в состав композитов на основе пористого магнитного стекла, избежав взаимодействия между формирующейся сегнетоэлектрической фазой и стекломатрицей.

Ключевые слова: глицин-нитратный синтез, метатитанат бария-стронция, ферромагнитные пористые стекла, мультиферроики.

DOI: $10.21883 /$ FTT.2019.12.48555.11ks

\section{1. Введение}

Метатитанат бария-стронция является электрокерамическим материалом, имеющим свойства как сегнетотак и параэлектрика. На сегодняшний день существуют как промышленные, так и лабораторные способы его получения [1-9], однако большинство низкотемпературных методов связано с процессами осаждения и гидратации, и поэтому требуют дополнительной высокотемпературной обработки для разложения прекурсоров и формирования кристаллической структуры перовскита. Актуальность разработки методов синтеза $\mathrm{BaTiO}_{3}$ и его твердых растворов сжиганием органо-солевых композиций связана с возможностью значительно снизить температуру и длительность температурной обработки, необходимой для синтеза сложных оксидов. Формируемые водные золи исходных композиций обладают низкой вязкостью, поэтому могут быть использованы для пропитки пористой ферромагнитной стекломатрицы с целью формирования композитных мультиферроиков. Данные материалы являются перспективными для современной твердотельной электроники, интерес к ним обусловлен возможностью эффективно управлять магнитными и электрическими свойствами с помощью внешних воздействий $[10,11]$. Пористые стекла выбраны в качестве матрицы неслучайно, они сочетают такие свойства как термическая и химическая устойчивость, стабильная диэлектрическая проницаемость и низкие потери $[12,13]$, которые выгодно отличают их от других пористых материалов. Поровое пространство стекол можно использовать как нанореактор для синтеза или импрегнирования различных веществ путем введения последних в поры из соответствующего солевого раствора, расплава или газовой фазы, что служит основой для получения композиционных материалов с заданными свойствами $[14,15]$. При этом ферромагнитная и сегнетоэлектрическая составляющие полученного композита будут разделены, что оказывает существенное влияние на функциональные свойства композитных мультиферроиков [14-16].

Целью данной работы являлось определение оптимальных параметров синтеза твердых растворов метатитаната бария-стронция методом сжигания глициннитратных композиций и изучение возможности использования разработанных композиций для формирования сегнетоэлектрической фазы на поверхности и в поровом пространстве ферромагнитных стекол для реализации композитных мультиферроиков.

\section{2. Экспериментальная часть}

Приготовление исходных смесей проводилось на основе гидратированного диоксида титана, который был получен взаимодействием $\mathrm{TiCl}_{4}$ с разбавленным аммиаком $\mathrm{NH}_{4} \mathrm{OH}$ при $\mathrm{pH}$ реакционной среды равном 9.5. Осадок отмывался от примесей, после чего растворялся 
в $1.4 \mathrm{~mol} / \mathrm{l}$ растворе азотной кислоты с образованием раствора $\mathrm{TiO}\left(\mathrm{NO}_{3}\right)_{2}$. Концентрация $\mathrm{TiO}_{2}$ в полученном растворе титанил-нитрата контролировалась весовым методом и составила $0.1 \mathrm{~g} / \mathrm{ml}$. В полученный раствор титанилнитрата, в соответствии со стехиометрией получаемого сложного оксида, вводились водные растворы $\mathrm{Ba}\left(\mathrm{NO}_{3}\right)_{2}$ или $\mathrm{Ba}\left(\mathrm{CH}_{3} \mathrm{COO}\right)_{2}$ и $\mathrm{Sr}\left(\mathrm{NO}_{3}\right)_{2}$, а также глицин. Были приготовлены растворы с разным содержанием нитрата стронция, соответствующие расчетной стехиометрии: $\mathrm{Ba}_{1-x} \mathrm{Sr}_{x} \mathrm{TiO}_{3}, x=0,0.1,0.2,0.3,0.4$.

Необходимый объем глицина $\left(\mathrm{C}_{2} \mathrm{H}_{5} \mathrm{NO}_{2}\right)$ рассчитывался, исходя из количества ионов азота в азотнокислых солях, входящих в состав композиции. Для полного восстановления азота, входящего в состав азотнокислых солей, необходимо чтобы выполнялось следующее соотношение: $n=5\left(\Sigma \mathrm{NO}_{3}\right) / m$, где $n-$ количество молей восстановителя на 1 моль продукта, а $m-$ число окисляемых связей в 1 молекуле органического вещества (для глицина $m=9$ ). В ходе эксперимента были приготовлены составы с количеством восстановителя, соответствующем расчетному, то есть с условным соотношением восстановителя и окислителя - $\varphi=1.0$, а также с меньшим $(\varphi=0.9)$, и большим $(\varphi=1.1,1.25)$ его содержанием.

После смешения полученные золи выдерживались в термостате при $80^{\circ} \mathrm{C}$ до испарения растворителя. Образовавшийся гель нагревался в фарфоровых тиглях в интервале температур $550-700^{\circ} \mathrm{C}$ с выдержкой при данной температуре от 0.5 до 3 часов, при этом формировались объемные пористые спеки белого цвета. Фазовый состав полученных образцов определялся методом рентгеновской дифрактометрии (XRD) с использованием дифрактометра ДРОН-3 (CuK $K_{\alpha}$-излучение).

Для выявления характера разложения ряда составов использовался метод комплексного термического анализа, заключающийся в проведении синхронной термогравиметрии (TG) и дифференциально-сканирующей калориметрии (DSC) одного и того же образца. Анализ проводился на термоанализаторе STA 429 (NETZSCH) в диапазоне температур от 25 до $900^{\circ} \mathrm{C}$ со скоростью нагрева и охлаждения $10^{\circ} / \mathrm{min}$, масса образцов составляла около $100 \mathrm{mg}$. Начало термического эффекта определялось по пересечению касательных к базовой линии кривых DSC и к начальной ветви кривой термического эффекта.

Для изучения возможности создания композитного мультиферроика на основе глицин-нитратных композиций, в качестве матрицы использовалось магнитное стекло в системе $\mathrm{K}_{2} \mathrm{O}-\mathrm{Fe}_{2} \mathrm{O}_{3}-\mathrm{SiO}_{2}$ [17], подвергнутое ионному обмену в расплаве нитрата натрия при $450^{\circ} \mathrm{C}$ в течение 9 часов для формирования пористой структуры. Пористость стекломатриц определялась методом стандартной эталонной порометрии на приборе Porosimeter 3.1. Более $82 \%$ пор в полученных стекломатрицах находилось в диапазоне от 1 до $30 \mu \mathrm{m}$. При этом средний размер пор составлял $7.9 \mu \mathrm{m}$, а удельная пористость - $0.033 \mathrm{~cm}^{3} / \mathrm{g}$. Полученные в результате эксперимента стекломатрицы $\mathrm{Na}_{2} \mathrm{O}-\mathrm{Fe}_{2} \mathrm{O}_{23}-\mathrm{SiO}_{2}$ (NFS) были пропитаны золями, соответствующими составам $\mathrm{BaTiO}_{3}$ и $\mathrm{Ba}_{0.7} \mathrm{Sr}_{0.3} \mathrm{TiO}_{3}$, высушены при температуре $80^{\circ} \mathrm{C}$ в течение 30 минут и обожжены в печи при температуре $550^{\circ} \mathrm{C}$ в течение 3 часов, в целях получения композитного материала, обладающего магнитными и сегнетоэлектрическими свойствами.

\section{3. Анализ и обсуждение результатов}

В ходе эксперимента было установлено, что при прокаливании глицин-нитратных композиций в интервале температур $550-650^{\circ} \mathrm{C}$ происходит формирование нанокристаллического титаната бария-стронция и неразложившихся примесей, количество которых зависит от характера горения полученных гелей.

По результатам комплексного термического анализа (рис. 1) горение всех глицин-нитратных композиций начинается при $180^{\circ} \mathrm{C}$ и в зависимости от содержания
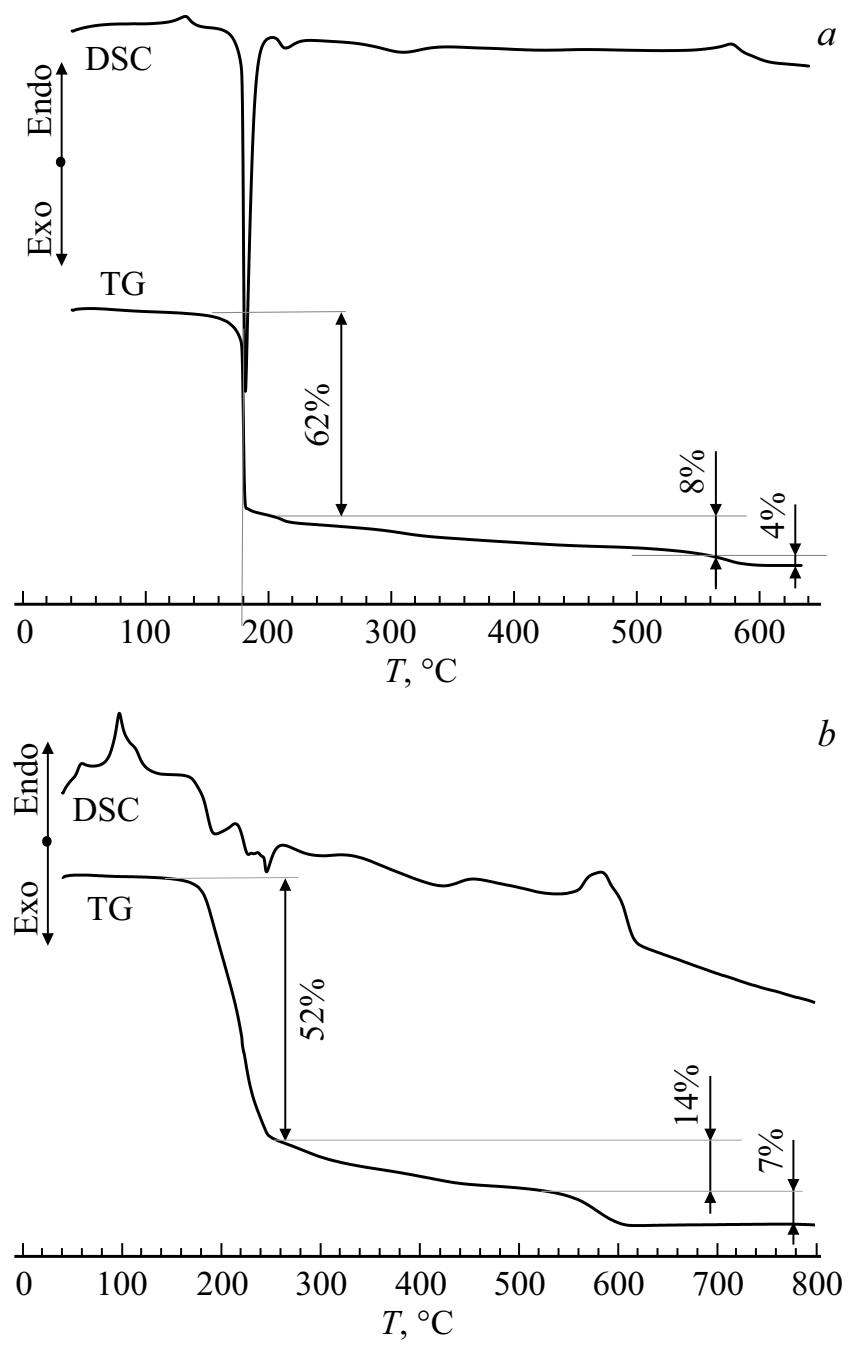

Рис. 1. Кривые DSC и TG образца состава $\mathrm{Ba}_{0.7} \mathrm{Sr}_{0.3} \mathrm{TiO}_{3}$ (a) - с исходным $\mathrm{pH}=2.5,(b)-\mathrm{c} \mathrm{pH}=2.7$. 
глицина имеет различный характер, либо объемного горения (рис. $1, a)$ - характеризующегося на кривой DSC очень узким интервалом разложения, либо самораспространяющегося синтеза (рис. $1, b)$ - в данном случае разложение происходит постепенно и разделяется на несколько отдельных этапов.

От характера горения зависит и потеря веса, связанная с разложением остатков нитратов, наблюдаемая в интервале температур $500-650^{\circ} \mathrm{C}$, минимальна она в режиме объемного горения, достигаемого при $\varphi=1.1$ без повышения $\mathrm{pH}$ исходного золя. Обжиг таких композиций при термообработке в интервале температур $550-580^{\circ} \mathrm{C}$ (ниже температуры размягчения используемой стекломатрицы) позволяет получать наноразмерные порошки твердых растворов $\mathrm{Ba}_{1-x} \mathrm{Sr}_{x} \mathrm{TiO}_{3}$ $(0 \leq x \leq 0.4)$ с минимальным содержанием примесных фаз. На рис. 2 приведены данные XRD анализа образцов состава $\mathrm{Ba}_{0.7} \mathrm{Sr}_{0.3} \mathrm{TiO}_{3}$, полученных сжиганием исходных композиций с различным содержанием глицина, где кривая 1 соответствует $\varphi=1.1$ и демонстрирует минимальное содержание вторичных фаз. Низкое содержание глицина в композиции $(\varphi=0.9)$ приводит к выходу из области объемного горения - получившиеся в этом случае порошки сильно аморфизованы (рис. 2, кривая 3), тогда как повышение содержания глицина $(\varphi=1.25)$ приводит к росту содержания примесного $\mathrm{BaCO}_{3}$ в порошке (рис. 2, кривая 2). Введение же в состав золей раствора аммиака для повышения $\mathrm{pH}$ смеси и улучшения комплексообразования приводит к переходу в режим самораспространяющегося синтеза, что может быть связано с увеличением в смеси содержания восстановителя за счет формирования $\mathrm{NH}_{4} \mathrm{NO}_{3}$ - полученные в таком режиме порошки сильнее вспучиваются при горении и характеризуются большим содержанием карбоната бария. Введение в состав композиций
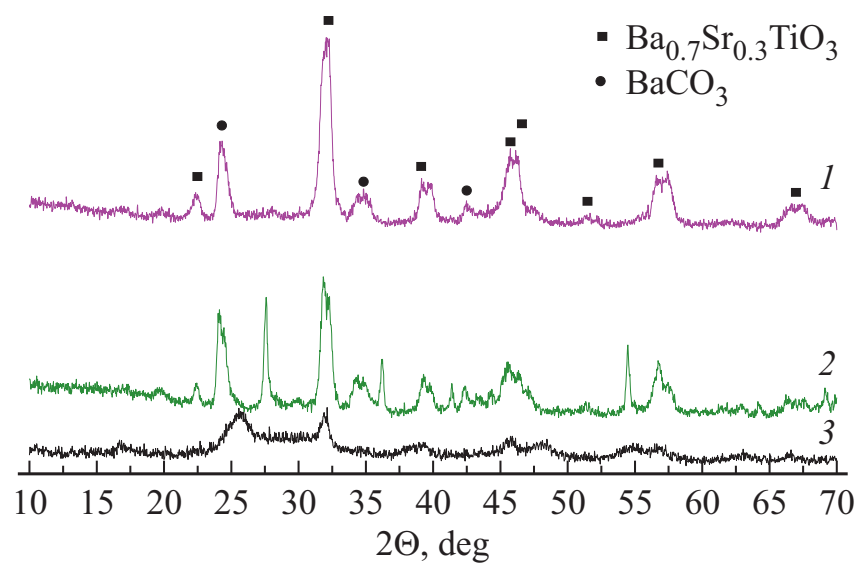

Рис. 2. Дифрактограммы образцов состава $\mathrm{Ba}_{0.7} \mathrm{Sr}_{0.3} \mathrm{TiO}_{3}$, полученных сжиганием исходных композиций с различным содержанием глицина, соответствующем (1) $\varphi=1.1$; (2) $\varphi=1.25 ;$ (3) $-\varphi=0.9$, при температуре $T=550^{\circ} \mathrm{C}$ в течение $3 \mathrm{~h}$.

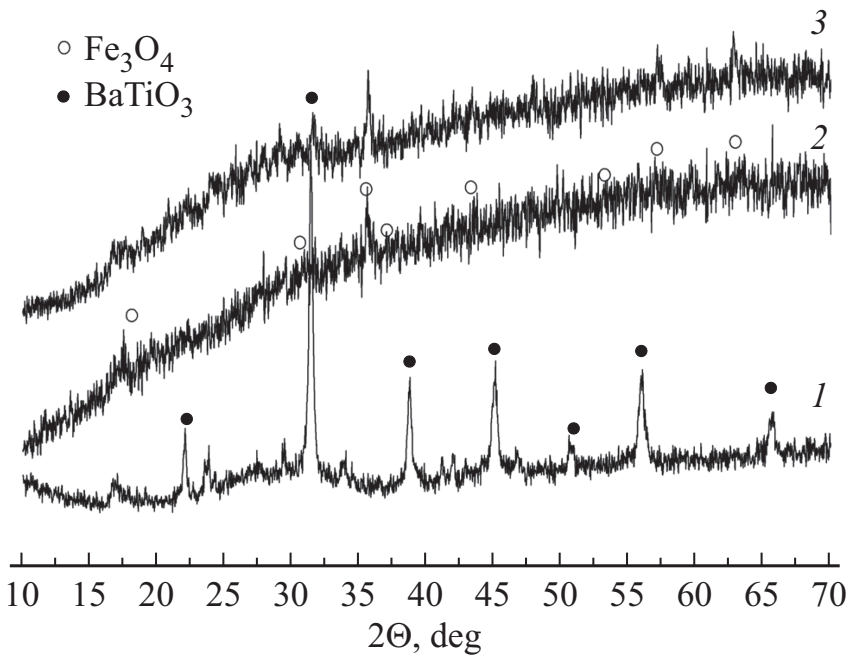

Рис. 3. Дифрактограммы $(1)-$ поверхностного слоя стекломатрицы NFS, после ее пропитки в золе и прокаливания при $T=550^{\circ} \mathrm{C}$ в течение $3 \mathrm{~h}$; (2) - исходного ферромагнитного стекла NFS и (3) - полученных композитов, содержащих $\mathrm{BaTiO}_{3}$, после удаления верхнего слоя с поверхности стекломатриц.

$\mathrm{Ba}\left(\mathrm{NO}_{3}\right)_{2}$ или $\mathrm{Ba}\left(\mathrm{CH}_{3} \mathrm{COO}\right)_{2}$ не влияет на характер разложения.

Полученные вышеописанным методом золи для синтеза твердых растворов использовались для пропитки пористых стекломатриц с целью формирования стеклокерамического композита, проявляющего мультиферроидные свойства.

В процессе термообработки, на поверхности и в поровом пространстве стекломатриц NFS формировался хорошо закристаллизованный твердый раствор, состав которого соответствовал исходной композиции, с низким содержанием примесных фаз, что подтверждается данными рентгенодифракционного анализа. На рис. 3 приведены данные XRD анализа стекломатрицы, пропитанной титанатом бария $(x=0)$, где кривая 1 соответствует дифрактограмме от поверхностного слоя. Для оценки присутствия титаната бария непосредственно в поровом пространстве, образовавшийся верхний слой на поверхности стекломатриц механически удалялся, после чего повторно проводился рентгенодифракционный анализ образца (рис. 3, кривая 3). Согласно угловым положениям рефлексов кристаллический $\mathrm{BaTiO}_{3}$ присутствует в порах матрицы, а снижение интенсивности пиков объясняется меньшим количеством материала в порах по сравнению с поверхностным слоем. Данные сканирующей микроскопии (рис. 4) и микрорентгеноспектрального анализа скола полученного композита c $\mathrm{BaTiO}_{3}$ подтверждают факт формирования титаната бария в порах по всем объему стекломатрицы. По результатам спектрального анализа, содержание титана и бария в композите составило, соответственно: 3.44 и 3.90 at $\%$. 


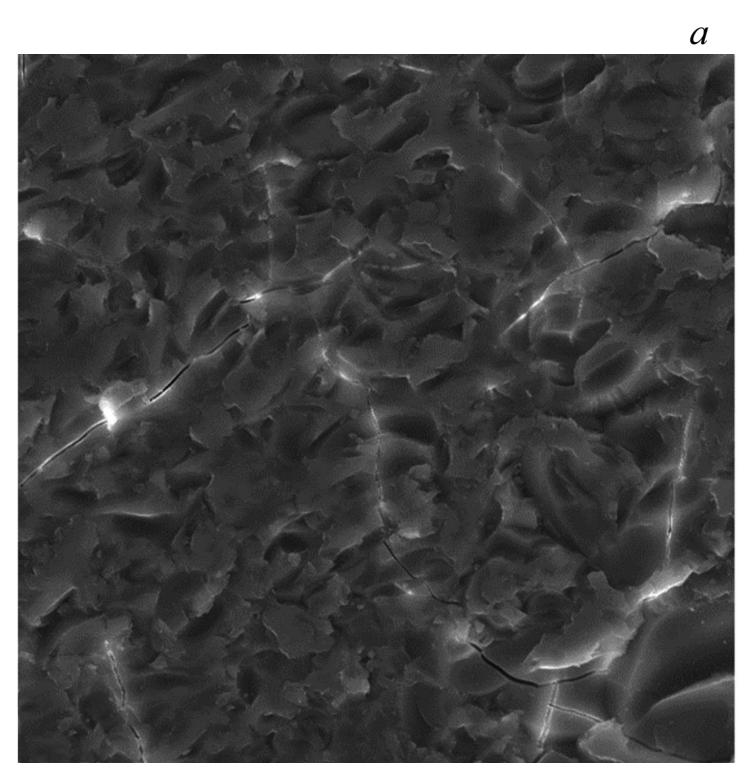

$-10 \mu \mathrm{m}$

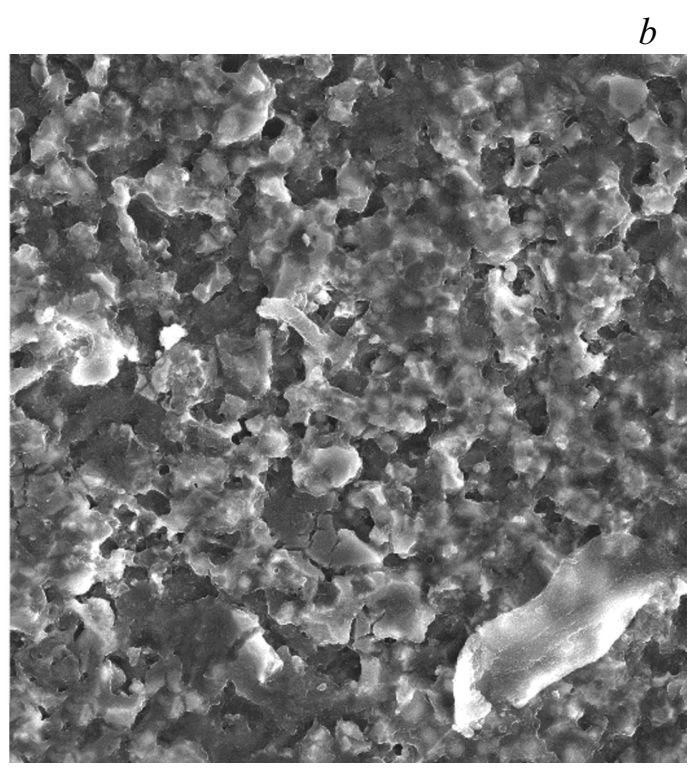

$-10 \mu \mathrm{m}$

Рис. 4. Микрофотографии сколов исходных стекломатриц NFS - $(a)$ и полученных композитов, содержащих $\mathrm{BaTiO}_{3}-(b)$.

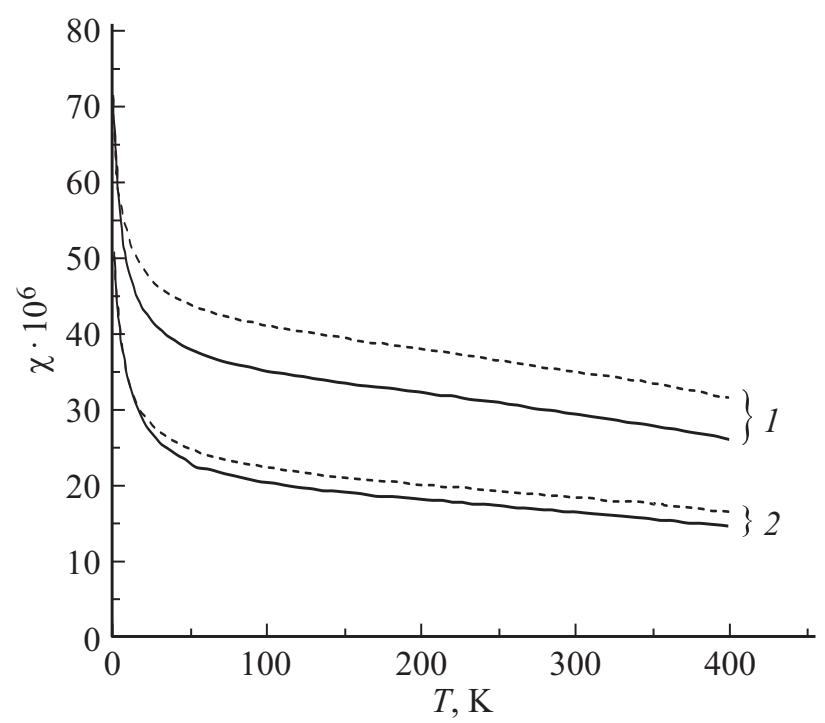

Рис. 5. Зависимости намагниченности от температуры для композитов на основе стекол $\mathrm{NFS} \mathrm{c} \mathrm{BaTiO}_{3}$ (1) и исходных пористых стекломатриц (2). Штриховые кривые сняты при $H=0.5 \mathrm{~T}$, сплошные - при $1.0 \mathrm{~T}$.

Зависимости намагниченности стеклокомпозитов на основе $\mathrm{BaTiO}_{3}$ и исходных пористых стекломатриц NFS от температуры, измеренные в различных магнитных полях, приведены на рис. 5. Магнитные характеристики, изученные с помощью СКВИД-магнетометра, показали значительное увеличение намагниченности сформированного композитного материала, по сравнению с исходной стекломатрицей. Дальнейшие исследования будут направленны на изучение сегнетоэлек- трических и мультиферроидных свойств полученных композитов.

\section{4. Заключение}

На основе глицин-нитратного метода разработана методика синтеза твердых растворов метатитаната бария-стронция $(0 \leq x \leq 0.4)$. Термообработка глициннитратных композиций, полученных при оптимальном соотношении восстановителя и окислителя $-\varphi=1.1$, в интервале температур $550-580^{\circ} \mathrm{C}$ (ниже температуры размягчения стекломатрицы) позволяет получать наноразмерные порошки твердых растворов $\mathrm{Ba}_{1-x} \mathrm{Sr}_{x} \mathrm{TiO}_{3}$ $(0 \leq x \leq 0.4)$ с минимальным содержанием примесных фаз.

В ходе пропитки магнитных пористых стекол золями предложенных глицин-нитратных композиций и последующей термообработки в поровом пространстве стекломатриц формируется кристаллический твердый раствор с низким содержанием примесных фаз, что подтверждается данными XRD и микрорентгеноспектрального анализа.

Исследование магнитных характеристик полученных стеклокерамических композитных материалов показало значительное увеличение намагниченности композита на основе титаната бария, включенного в пористую матрицу, по сравнению с исходной ферромагнитной стекломатрицей.

\section{Финансирование работы}

Работа выполнена при финансовой поддержке РФФИ (проект № 19-07-00600) и Минобрнауки России (государственное задание № 3.3990.2017/4.6). 


\section{Конфликт интересов}

Авторы заявляют об отсутствии конфликта интересов.

\section{Список литературы}

[1] G. Pfaff, A. Feltz. Crys. Res. Technol. 25, 1039 (1990).

[2] Y.S. Malghe, A.V. Gurjar, S.R. Dharwadkar. Bull. Mater. Sci. 27, 217 (2004).

[3] В.А. Жабрев, Л.П. Ефименко, В.Г. Барышников, И.Г. Полякова, А.В. Гуменников. Физика и химия стекла 34, 116 (2008).

[4] M.E.A. Araghi, N. Shaban, M. Bahar. Mater. Sci.-Poland 34, 63 (2016).

[5] M. Cernea. J. Optoelectron. Adv. Mater. 7, 3015 (2005).

[6] Т.В. Ким, Н.В. Гапоненко, Е.А. Степанова, Т.Ф. Кузнецова, А.И. Ратько. Журн. прикл. спектроскопии 76, 884 (2009).

[7] A. Kuzmenko, A. Sizov, O. Yacovlev, N. Emelianov. J. NanoElectron. Phys. 5, 04024 (2013).

[8] S. Gijp, L. Winnubst, H. Verweij. J. Am. Ceram. Soc. 82, 1175 (1999).

[9] Z. Zhong, P.K. Gallagher. Mater. Sci. 10, 945 (1995).

[10] C.-W. Nan, M.I. Bichurin, S. Dong, D. Viehland, G. Srinivasan. J. Appl. Phys. 103, 031101 (2008).

[11] А.П. Пятаков, А.К. Звездин. Успехи физ. наук 182, 593 (2012).

[12] J.M. Wu, H.L. Huang. J. Non-Cryst. Solids 260, 116 (1999).

[13] M. Letz. In book: Microwave Materials and Applications / Ed. M.T. Sebastian, H. Jantunen, R. Ubic. John Wiley \& Sons Ltd. 1, 345 (2017).

[14] A. Ciżman, K. Rogacki, E. Rysiakiewicz-Pasek, T. Antropova, O. Pshenko, R. Poprawski. J. Alloys Comp. 649, 447 (2015).

[15] E.V. Charnaya, M.K. Lee, C. Tien, V.N. Pak, D.V. Formus, A.L. Pirozerskii, A.I.Nedbai, E.V. Ubyivovk, S.V. Baryshnikov, L.J. Chang. J. Magn. Magn. Mater. 324, 2921 (2012).

[16] S.Q. Ren, L.Q. Weng, S.H. Song. J. Mater. Sci. 40, 4375 (2005).

[17] С.И. Свиридов, 3.Г. Тюрнина, Н.Г. Тюрнина, Л.Ю. Крючкова, Н.С. Власенко. Физика и химия стекла 43, 41 (2017).

Редактор Д.В. Жуманов 